\title{
Low-Threshold-Voltage TaN/LaTiO n-MOSFETs With Small EOT
}

\author{
S. H. Lin, C. H. Cheng, W. B. Chen, F. S. Yeh, and Albert Chin
}

\begin{abstract}
In this letter, we report a low threshold voltage $\left(V_{t}\right)$ of $0.12 \mathrm{~V}$ in self-aligned gate-first TaN/LaTiO n-MOSFETs, at an equivalent oxide thickness of only $0.63 \mathrm{~nm}$. This was achieved by using Ni-induced solid-phase diffusion of $\mathrm{SiO}_{2}$-covered $\mathrm{Ni} / \mathrm{Sb}$ that reduced the high- $\kappa$ dielectric interfacial reactions.
\end{abstract}

Index Terms-LaTiO, low $V_{t}$, solid-phase diffusion (SPD).

\section{INTRODUCTION}

A DIFFICULT challenge for metal-gate/high- $\kappa$ CMOS [1][13] is to suppress the undesirable large flatband voltage $\left(V_{\mathrm{fb}}\right)$ rolloff [7], [8] at smaller equivalent oxide thickness (EOT), which leads to an unwanted high threshold voltage $\left(V_{t}\right)$. To address this issue, an ultrathin $\mathrm{SiO}_{2}$ layer can be inserted between the high- $\kappa$ dielectric and $\mathrm{Si}$ as used in the 45-nm-node technology with a 1-nm EOT [9]. However, this may not work when the EOT is scaled down to $\sim 0.6 \mathrm{~nm}$. Previously, we have shown that the $V_{\mathrm{fb}}$ rolloff and the high $V_{t}$ are related to chargedoxygen vacancies in the nonstoichiometric oxides $\left(\mathrm{HfO}_{2-x}\right.$ and $\mathrm{SiO}_{x}$ ) [7], [8]. This occurs via an inevitable interfacial reaction and interdiffusion [7] due to the close bond enthalpies of the high- $\kappa \mathrm{HfO}_{2}(802 \mathrm{~kJ} / \mathrm{mol})$ and the $\mathrm{SiO}_{2}(800 \mathrm{~kJ} / \mathrm{mol})$ [3]. Since this reaction follows an Arrhenius temperature dependence, it can be reduced by using low-temperature processing. This has been verified by the low $\left|V_{t}\right|$ obtained in metal-gate/ high- $\kappa$ CMOS with EOT of $1.05-1.2 \mathrm{~nm}$, using $<900{ }^{\circ} \mathrm{C}$ solidphase-diffusion (SPD)-formed ultrashallow junctions [7] and laser annealing [8]. In this letter, we report a low $V_{t}$ of $0.12 \mathrm{~V}$ in TaN/LaTiO n-MOSFETs with an EOT of only $0.63 \mathrm{~nm}$. This was achieved by using higher $\kappa \mathrm{LaTiO}$ to decrease the gate leakage current and low-temperature Ni-induced SPD for sourcedrain to lower high $-\kappa / \mathrm{Si}$ interface reaction exponentially.

Manuscript received May 15, 2009; revised June 21, 2009. First published August 19, 2009; current version published August 27, 2009. This work was supported in part by the National Science Council of Taiwan under Grant NSC 97-2120-M-009-008. The review of this letter was arranged by Editor M. Ostling.

S. H. Lin and F. S. Yeh are with the Department of Electrical Engineering, National Tsing Hua University, Hsinchu 300, Taiwan (e-mail: d9563815@oz.nthu.edu.tw; fsyeh@ee.nthu.edu.tw).

C. H. Cheng is with the Department of Mechanical Engineering, National Chiao Tung University, Hsinchu 300, Taiwan, and also with Taiwan Semiconductor Manufacturing Company, Ltd., Hsinchu 300, Taiwan (e-mail: feldcheng@hotmail.com).

W. B. Chen is with the Department of Electronics Engineering, National Chiao Tung University, Hsinchu 300, Taiwan (e-mail: barn.ee95g@ nctu.edu.tw).

A. Chin is with the Department of Electronics Engineering, National Chiao Tung University, Hsinchu 300, Taiwan, and also with Nano-Electronics Consortium of Taiwan, Hsinchu 300, Taiwan (e-mail: albert_achin@ @otmail.com).

Color versions of one or more of the figures in this letter are available online at http://ieeexplore.ieee.org.

Digital Object Identifier 10.1109/LED.2009.2027723

\section{EXPERIMENTAL PROCEDURE}

Standard p-type $\mathrm{Si}$ wafers were used in this letter. The self-aligned gate-first TaN/LaTiO n-MOSFETs were made by depositing $\mathrm{TiO}_{2}$-doped $\mathrm{La}_{2} \mathrm{O}_{3}$ (LaTiO with $\sim 25 \% \mathrm{TiO}$ concentration) on $\mathrm{Si}$ substrate using physical-vapor deposition, followed by a postdeposition anneal (PDA). The addition of $\mathrm{TiO}_{2}$ in LaTiO increases the $\kappa$ value, which allows the using of a thicker layer to decrease the leakage current and still maintains the small EOT. After TaN deposition and patterning, self-aligned 20-nm Sb and thin Ni were deposited. This was covered with 100 -nm-thick $\mathrm{SiO}_{2}$ followed by a $650{ }^{\circ} \mathrm{C}$ RTA [13]. A low sheet resistance of $125 \Omega$ /sq was measured using $\mathrm{SiO}_{2}$-covered Ni/Sb SPD at $650{ }^{\circ} \mathrm{C}$. After etching nonreacted metal, $\mathrm{Al}$ contact metal was added on source-drain to form the $\mathrm{n}$-MOSFETs with $10 \mu \mathrm{m} \times 100 \mu \mathrm{m}$ size. The interface reaction was investigated by secondary ion-mass spectroscopy (SIMS) and transmission electron microscopy (TEM). The fabricated n-MOSFETs were characterized by capacitance-voltage $(C-V)$ and current-voltage $(I-V)$ measurements.

\section{Results AND Discussion}

Fig. 1(a) and (b) shows the $C-V$ and $J-V$ curves of TaN/LaTiO n-MOS devices at various RTA temperatures. High capacitance density of $3.4 \mu \mathrm{F} / \mathrm{cm}^{2}$, leakage current of $5 \times$ $10^{-2} \mathrm{~A} / \mathrm{cm}^{2}$ at $-1 \mathrm{~V}$, and proper $V_{\mathrm{fb}}$ of $-0.52 \mathrm{~V}$ were obtained after a $600{ }^{\circ} \mathrm{C}$ RTA. This gives an EOT of $0.63 \mathrm{~nm}$ by CVC quantum-mechanical $C-V$ simulation, which can be used for 25-nm-node technology with 10-nm gate length at year 2015 according to ITRS [14]. The negative $V_{\mathrm{fb}}$ is a unique property of $\mathrm{La}_{2} \mathrm{O}_{3}$ even with the TaN gate [6]. However, both unwanted EOT degradation and $V_{\mathrm{fb}}$ rolloff from -0.52 to $-0.27 \mathrm{~V}$ were found with increasing RTA temperature from $600{ }^{\circ} \mathrm{C}$ to $900{ }^{\circ} \mathrm{C}$. The TEM images of $600{ }^{\circ} \mathrm{C}$ and $900{ }^{\circ} \mathrm{C}$ RTA samples were also inserted in Fig. 1(a) and (b), respectively. The thickness of the interfacial layer increases with increasing RTA temperature from $600{ }^{\circ} \mathrm{C}$ to $900{ }^{\circ} \mathrm{C}$, which matches well the decreasing capacitance density. Such interfacial-layer formation is unavoidable because of the strong bond enthalpy of $\mathrm{Si}-\mathrm{O}$ $(800 \mathrm{~kJ} / \mathrm{mol})$ close to La-O $(799 \mathrm{~kJ} / \mathrm{mol})$ but higher than Ti-O $(672 \mathrm{~kJ} / \mathrm{mol})[3]$.

$$
\mathrm{Si}+\mathrm{LaTiO}_{m} \underset{\Delta}{\longrightarrow} \mathrm{SiO}_{x}+\mathrm{LaTiO}_{m-x}
$$

We further used SIMS to study these phenomena. Fig. 2 shows the SIMS profile of the earlier MOS structure after $600{ }^{\circ} \mathrm{C}$ and $800^{\circ} \mathrm{C}$ RTA. The interdiffusion of the Ti and $\mathrm{Si}$ was 


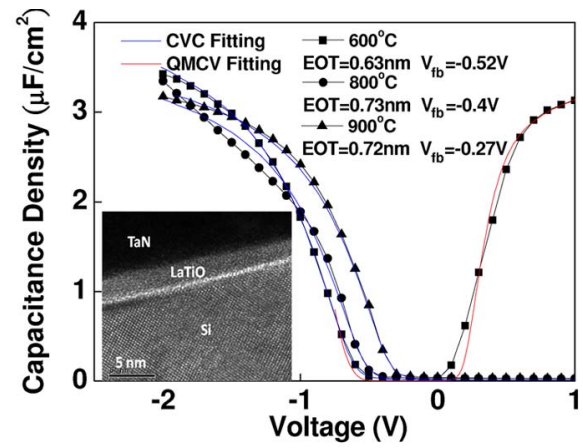

(a)

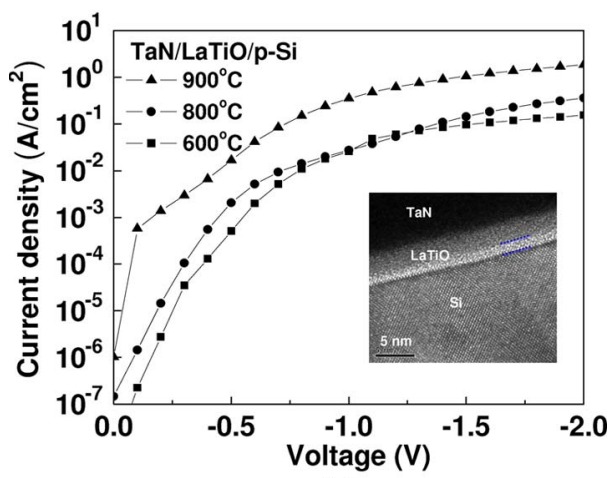

(b)

Fig. 1. PDA temperature dependence of (a) $C-V$ and (b) $J-V$ characteristics of TaN/LaTiO/p-Si n-MOS devices. The $600{ }^{\circ} \mathrm{C}$ data were measured in a MOSFET from accumulation to inversion, while the $800^{\circ} \mathrm{C}$ and $900^{\circ} \mathrm{C}$ data were measured in MOS capacitors from accumulation to depletion. The inserted TEM images in (a) and (b) are the samples after $600{ }^{\circ} \mathrm{C}$ and $900{ }^{\circ} \mathrm{C}$ RTA.

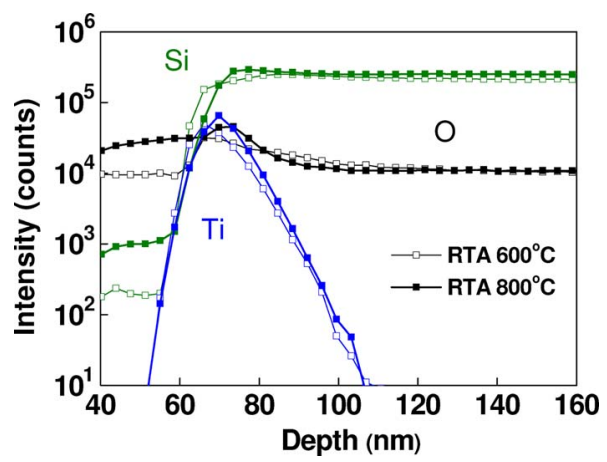

Fig. 2. SIMS profile of LaTiO after $600^{\circ} \mathrm{C}$ and $800^{\circ} \mathrm{C}$ RTA treatments.

found with increasing the RTA temperature. The oxygen peak in the high- $\kappa$ dielectric shifts toward the Si, suggesting the formation of interfacial silicate from thermal-dynamic considerations [7]. This interface layer is further observed by cross-sectional TEM, which is unavoidable unless a thick enough interfacial $\mathrm{SiO}_{2}$ is inserted between high- $\kappa$ and $\mathrm{Si}$ to decrease the interface reaction and interdiffusion.

This additional interfacial layer cannot explain the unexpected leakage-current increase after $900{ }^{\circ} \mathrm{C}$ RTA. We have used X-ray diffraction to measure the crystallinity of the LaTiO after various RTA. The amorphous LaTiO becomes crystallized at $900{ }^{\circ} \mathrm{C}$ RTA. Therefore, the higher leakage current after the $900{ }^{\circ} \mathrm{C}$ RTA may be related to the formation of polycrystals that provide extra leakage paths through highly defective grain

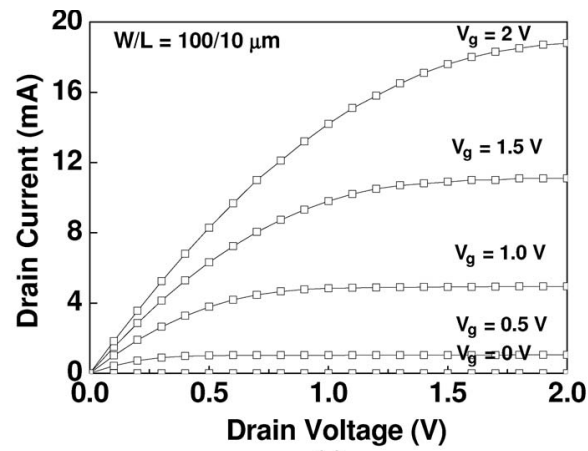

(a)

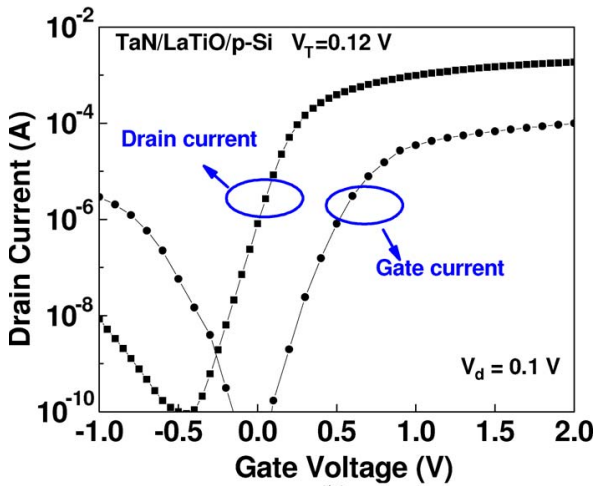

(b)

Fig. 3. (a) $I_{d}-V_{d}$ and (b) $I_{d}-V_{g}$ and $I_{g}-V_{g}$ characteristics of self-aligned gate-first n-MOSFETs, where the LaTiO gate dielectric is treated with a $600{ }^{\circ} \mathrm{C}$ RTA

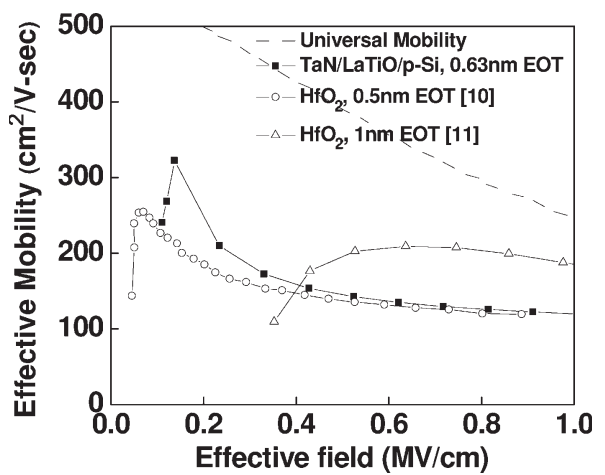

Fig. 4. Electron mobility of the n-MOSFETs extracted from the $I_{d}-V_{g}$ curves shown in Fig. 3(b).

boundaries [15]. This further emphasizes the importance of the proposed low-temperature processing.

To lower the interfacial reaction, we have used Ni-induced SPD for source-drain regions of TaN/LaTiO n-MOSFET. Fig. 3(a) and (b) shows the $I_{d}-V_{d}$ and $I_{d}-V_{g}$ characteristics. Besides the good transistor characteristics, a low $V_{t}$ of $0.12 \mathrm{~V}$ was measured at $0.63-\mathrm{nm}$ EOT. Fig. 4 shows the effective mobility derived directly from the $I_{d}-V_{g}$ curves. The mobility data of $0.5-\mathrm{nm}$ EOT $\mathrm{NiSi} / \mathrm{HfO}_{2} / \mathrm{HfSiO}_{x}$ and $1.0-\mathrm{nm}$ EOT $\mathrm{TiN} / \mathrm{HfO}_{2}$ n-MOSFETs were also plotted for comparison [10], [11]. A mobility of $126 \mathrm{~cm}^{2} / \mathrm{V} \cdot \mathrm{s}$ was obtained in TaN/LaTiO $\mathrm{n}$-MOSFET at $0.8 \mathrm{MV} / \mathrm{cm}$ with a $0.63-\mathrm{nm}$ EOT. This value is slightly higher that for $\mathrm{NiSi} / \mathrm{HfO}_{2} / \mathrm{HfSiO}_{x}$ device at $0.5-\mathrm{nm}$ EOT [10], along with a very low $V_{t}$ of 0.12 V. Such 
low $V_{t}$ is due to the unique negative $V_{\mathrm{fb}}$ of $\mathrm{La}_{2} \mathrm{O}_{3}$ dielectric. However, the mobility is significantly smaller than the $\mathrm{TiN} / \mathrm{HfO}_{2}$ n-MOSFET at 1.0-nm EOT [11]. Similar mobility decrease with decreasing EOT was also reported in the literature [10], [12]. Such mobility degradation at small EOT is unavoidable due to the less interfacial $\mathrm{SiO}_{x}$ allowed at thinner EOT. This further increases the interface charged-oxygen vacancies in (1) formed by interface reaction and interdiffusion after standard $1000^{\circ} \mathrm{C}$ RTA. Further mobility improvement can be reached by adding an ultrathin $\mathrm{SiON}$, although this is traded off by the EOT scaling.

\section{CONCLUSION}

Using a simple process, we have fabricated metal-gate/ high- $\kappa$ TaN/LaTiO n-MOSFET with a low $V_{t}$ of $0.12 \mathrm{~V}$ at $0.63-\mathrm{nm}$ EOT. Besides, this device has the advantages of simple self-aligned and gate-first process compatible with current VLSI.

\section{REFERENCES}

[1] H.-H. Tseng, C. C. Capasso, J. K. Schaeffer, E. A. Hebert, P. J. Tobin, D. C. Gilmer, D. Triyoso, M. E. Ramón, S. Kalpat, E. Luckowski, W. J. Taylor, Y. Jeon, O. Adetutu, R. I. Hegde, R. Noble, M. Jahanbani, C. El Chemali, and B. E. White, "Improved short channel device characteristics with stress relieved pre-oxide (SRPO) and a novel tantalum carbon alloy metal gate/HfO2 stack," in IEDM Tech. Dig., 2004, pp. 821-824.

[2] T. Nabatame, M. Kadoshima, K. Iwamoto, N. Mise, S. Migita, M. Ohno, H. Ota, N. Yasuda, A. Ogawa, K. Tominaga, H. Satake, and A. Toriumi, "Partial silicides technology for tunable work function electrodes on high-k gate dielectrics-Fermi level pinning controlled $\mathrm{PtSi}_{x}$ for $\mathrm{HfO}_{x}(\mathrm{~N})$ pMOSFET," in IEDM Tech. Dig., 2004, pp. 83-86.

[3] D. S. Yu, A. Chin, C. H. Wu, M.-F. Li, C. Zhu, S. J. Wang, W. J. Yoo, B. F. Hung, and S. P. McAlister, "Lanthanide and Ir-based dual metal-gate/ HfAlON CMOS with large work-function difference," in IEDM Tech. Dig., 2005, pp. 649-652.

[4] C. H. Wu, D. S. Yu, A. Chin, S. J. Wang, M.-F. Li, C. Zhu, B. F. Hung, and S. P. McAlister, "High work function $\operatorname{Ir}_{x} \mathrm{Si}$ gates on HfAlON p-MOSFETs," IEEE Electron Device Lett., vol. 27, no. 2, pp. 90-92, Feb. 2006.
[5] X. P. Wang, C. Shen, M.-F. Li, H. Y. Yu, Y. Sun, Y. P. Feng, A. Lim, H. W. Sik, A. Chin, Y. C. Yeo, P. Lo, and D. L. Kwong, "Dual metal gates with band-edge work functions on novel HfLaO high- $\kappa$ gate dielectric," in VLSI Symp. Tech. Dig., 2006, pp. 12-13.

[6] C. H. Wu, B. F. Hung, A. Chin, S. J. Wang, X. P. Wang, M.-F. Li, C. Zhu, Y. Jin, H. J. Tao, S. C. Chen, and M. S. Liang, "High temperature stable $\left[\mathrm{Ir}_{3} \mathrm{Si}-\mathrm{TaN}\right] / \mathrm{HfLaON}$ CMOS with large work-function difference," in IEDM Tech. Dig., 2006, pp. 617-620.

[7] C. F. Cheng, C. H. Wu, N. C. Su, S. J. Wang, S. P. McAlister, and A. Chin, "Very low $\mathrm{V}_{t}[\mathrm{Ir}-\mathrm{Hf}] / \mathrm{HfLaO}$ CMOS using novel selfaligned low temperature shallow junctions," in IEDM Tech. Dig., 2007, pp. 333-336.

[8] C. C. Liao, A. Chin, N. C. Su, M.-F. Li, and S. J. Wang, "Low $V_{t}$ gatefirst $\mathrm{Al} / \mathrm{TaN} /\left[\mathrm{Ir}_{3} \mathrm{Si}-\mathrm{HfSi}_{2-x}\right] / \mathrm{HfLaON} \mathrm{CMOS}$ using simple process," in VLSI Symp. Tech. Dig., 2008, pp. 190-191.

[9] K. Mistry, C. Allen, C. Auth, B. Beattie, D. Bergstrom, M. Bost, M. Brazier, M. Buehler, A. Cappellani, R. Chau, C.-H. Choi, G. Ding, K. Fischer, T. Ghani, R. Grover, W. Han, D. Hanken, M. Hattendorf, J. He, J. Hicks, R. Huessner, D. Ingerly, P. Jain, R. James, L. Jong, S. Joshi, C. Kenyon, K. Kuhn, K. Lee, H. Liu, J. Maiz, B. McIntyre, P. Moon, J. Neirynck, S. Pae, C. Parker, D. Parsons, C. Prasad, L. Pipes, M. Prince, P. Ranade, T. Reynolds, J. Sandford, L. Shifren, J. Sebastian, J. Seiple, D. Simon, S. Sivakumar, P. Smith, C. Thomas, T. Troeger, P. Vandervoorn, S. Williams, and K. Zawadzki, "A $45 \mathrm{~nm}$ logic technology with high-k+metal gate transistors, strained silicon, $9 \mathrm{Cu}$ interconnect layers, $193 \mathrm{~nm}$ dry patterning, and 100\% Pb-free packaging," in IEDM Tech. Dig., 2007, pp. 247-250.

[10] M. Takahashi, A. Ogawa, A. Hirano, Y. Kamimuta, Y. Watanabe, K. Iwamoto, S. Migita, N. Yasuda, H. Ota, T. Nabatame, and A. Toriumi, "Gate-first processed $\mathrm{FUSI} / \mathrm{HfO}_{2} / \mathrm{HfSiO}_{x} / \mathrm{Si}$ MOSFETs with EOT = $0.5 \mathrm{~nm}$-Interfacial layer formation by cycle-by-cycle deposition and annealing," in IEDM Tech. Dig., 2007, pp. 523-526.

[11] S. Datta, G. Dewey, M. Doczy, B. S. Doyle, B. Jin, J. Kavalieros, R. Kotlyar, M. Metz, N. Zelick, and R. Chau, "High mobility Si/SiGe strained channel MOS transistors with $\mathrm{HfO}_{2} / \mathrm{TiN}$ gate stack," in IEDM Tech. Dig., 2003, pp. 653-656.

[12] W. Tsai, L.-Å. Ragnarsson, L. Pantisano, P. J. Chen, B. Onsia, T. Schram, E. Cartier, A. Kerber, E. Young, M. Caymax, S. De Gendt, and M. Heyns, "Performance comparison of sub $1 \mathrm{~nm}$ sputtered TiN/HfO 2 nMOS and pMOSFETs," in IEDM Tech. Dig., 2003, pp. 311-314.

[13] S. H. Lin, S. L. Liu, F. S. Yeh, and A. Chin, "Low $V_{t}$ TaN/HfLaO $n$-MOSFETs using low temperature formed source-drain junctions," IEEE Electron Device Lett., vol. 30, no. 1, pp. 75-77, Jan. 2009.

[14] International Technology Roadmap for Semiconductors, Process Integration, Devices, and Structures Chapter, p. 11. [Online]. Available: www.itrs.net/Links/2007ITRS/2007_Chapters/2007_PIDS.pdf

[15] K. C. Chiang, A. Chin, C. H. Lai, W. J. Chen, C. F. Cheng, B. F. Hung, and C. C. Liao, "Very high $\kappa$ and high density TiTaO MIM capacitors for analog and RF applications," in VLSI Symp. Tech. Dig., 2005, pp. 62-63. 